\title{
Article \\ Multielement Ring Array Based on Minute Size PMUTs for High Acoustic Pressure and Tunable Focus Depth
}

\author{
Eyglis Ledesma (D), Iván Zamora ${ }^{(D)}$, Arantxa Uranga ${ }^{(D)}$ and Núria Barniol *D \\ Departament d'Enginyeria Electrònica, Universitat Autónoma de Barcelona, 08193 Bellaterra, Spain; \\ eyglis.ledesma@uab.es (E.L.); ivan.zamora@uab.es (I.Z.); arantxa.uranga@uab.es (A.U.) \\ * Correspondence: nuria.barniol@uab.es
}

check for updates

Citation: Ledesma, E.; Zamora, I.; Uranga, A.; Barniol, N. Multielement Ring Array Based on Minute Size PMUTs for High Acoustic Pressure and Tunable Focus Depth. Sensors 2021, 21, 4786. https://doi.org/ $10.3390 / \mathrm{s} 21144786$

Academic Editor: Anthony N. Sinclair

Received: 22 June 2021

Accepted: 10 July 2021

Published: 13 July 2021

Publisher's Note: MDPI stays neutral with regard to jurisdictional claims in published maps and institutional affiliations.

Copyright: (c) 2021 by the authors. Licensee MDPI, Basel, Switzerland. This article is an open access article distributed under the terms and conditions of the Creative Commons Attribution (CC BY) license (https:// creativecommons.org/licenses/by/ $4.0 /)$.
Abstract: This paper presents a multielement annular ring ultrasound transducer formed by individual high-frequency PMUTs (17.5 MHz in air and 8.7 MHz in liquid) intended for high-precision axial focalization and high-performance ultrasound imaging. The prototype has five independent multielement rings fabricated by a monolithic process over CMOS, allowing for a very compact and robust design. Crosstalk between rings is under $56 \mathrm{~dB}$, which guarantees an efficient beam focusing on a range between $1.4 \mathrm{~mm}$ and $67 \mu \mathrm{m}$. The presented PMUT-on-CMOS annular array with an overall diameter down to $669 \mu \mathrm{m}$ achieves an output pressure in liquid of $4.84 \mathrm{kPa} / \mathrm{V} / \mathrm{mm}^{2}$ at $1.5 \mathrm{~mm}$ away from the array when the five channels are excited together, which is the largest reported for PMUTs. Pulse-echo experiments towards high-resolution imaging are demonstrated using the central ring as a receiver. With an equivalent diameter of $149 \mu \mathrm{m}$, this central ring provides high receiving sensitivity, $441.6 \mathrm{nV} / \mathrm{Pa}$, higher than that of commercial hydrophones with equivalent size. A 1D ultrasound image using two channels is demonstrated, with maximum received signals of $7 \mathrm{mVpp}$ when a nonintegrated amplifier is used, demonstrating the ultrasound imaging capabilities.

Keywords: PMUTs; annular array; ring array; ultrasound; AlN; ultrasound imaging; pulse-echo; PMUT-on-CMOS

\section{Introduction}

Ultrasound is widely used as an excellent noninvasive diagnostic tool for nondestructive testing and medical imaging. Nowadays, small ultrasound probes are being extensively pursued in areas such as in-body controllable catheter-based imaging for intravascular imaging [1-4], specific heat treatments based on high-intensity focused ultrasound (HIFU systems) [5,6], or brain stimulation for in vivo experiments [7,8]. In addition to these applications, power-free implantable prostheses for sensing biological parameters in animals or humans are also a rapidly evolving field of research towards digital medicine and in view of elderly population growth. Recently, powering and data transfer for these devices by ultrasound is being studied and presented as one of the alternatives in comparison with radiofrequency and inductive links [9-11].

For all these cases, tiny ultrasound transducers with very controllable and tunable focus depth are required. Among the different ultrasound probes, annular rings provide by layout this capability. Their dynamic focusing along the axial direction and their symmetry produce an acoustic pattern with a high spatial resolution (lateral and axial) and high levels of output pressure which have been efficiently used in most of the above-mentioned applications [1,3-6,8,9].

Annular rings for ultrasound systems have been fabricated with bulk piezoelectric materials in their thickness vibration mode. However, their complex fabrication process would limit their use in advanced ultrasound systems which require minute sizes, high reproducibility, cost-efficiency, and low power consumption [12,13]. Advances in the fabrication of micromachined ultrasonic transducers using MEMS-based technologies, either capacitive (CMUTs) or piezoelectrical (PMUTs) with the capability of direct integration 
with CMOS, in a batch processing approach, decrease manufacturing cost and allow a reduction in size and increase in compactness of the overall ultrasound system [12,14,15]. Ring-shaped CMUT arrays have been widely described in the literature [3-5,12,14]. However, their eligibility can be affected by the high power consumption needed in the CMUT transducers. On the contrary, monolithic ultrasound systems based on PMUTs open the way to power-efficient single-chip ultrasound systems [15,16].

In PMUTs, the ultrasound wave is produced due to the flexural movement of the membrane, and its operational frequency will depend on both the different thicknesses of the material and the size of the transducer, allowing in this way different operation frequencies using different device layouts but with the same technological approach. Few examples of continuous annular rings under this flexural approach have been reported [6]. However, continuous annular array fabrication could be a challenge due to its dimensional constraints. In order to avoid this and increase the achievable output pressure at the acoustic axis, a finite number of small ultrasound transducers configured in an annular ring can be used (see for example $[1,17]$ ). The main advantage in this multielement ring configuration is given by the capability to decouple the acoustic wave frequency, due exclusively to the single element, from the overall ring diameter, keeping a longer-range tunable focus depth, as is shown in Section 2. Taking these demands into consideration, we have designed a multiple concentric annular ring ultrasonic transducer composed of multiple high-frequency piezoelectrical micromachined ultrasound transducers (PMUTs) capable of being monolithically integrated with CMOS technology [16]. The fabricated multielement ring ultrasound array provides high accurate tunable focus depth, high acoustic output pressure, and minute size which is operable in the $10 \mathrm{MHz}$ frequency range in a liquid environment and can be a candidate for the above-mentioned applications. In addition, we have characterized the central ring of the array as an ultrasonic receiver, showing higher receiver sensitivity with smaller spatial averaging effects than commercial hydrophones with similar size.

This paper is organized into four sections: Section 2 explains the multielement ring array design and its benefit over the continuous ring array using analytical equations and FEM simulations (COMSOL Multiphysics); predictions of the acoustic performance with Field II software are also provided. Section 3 shows the experimental results, including the electrical and acoustic characterization and line-scan ultrasound imaging as a demonstration of the full transceiver ultrasound system. Finally, Section 4 concludes the paper.

\section{Materials and Methods}

\subsection{Multielement Ring Array Design}

As already explained, the main advantage of an annular ring is its capability to be axially focused; focus depth tunability, beam diameter at the focus point, and range of achievable pressure are its main parameters. The focus depth, $F_{d}$, is defined by Equation (1), where $S$ is the transducer area (whatever its shape), $\lambda$ is the wavelength, $f$ is the frequency, and $c$ is the sound velocity in the propagation medium [18]. It is evident that transducers with the same area will produce a greater focus depth with higher frequency.

$$
F_{d}=\frac{S}{4 \lambda}=\frac{S \times f}{4 \times c}
$$

For the design of an efficient annular ring, the first question is how we can achieve the highest frequency using the same transducer area, which will give us the greatest focus depth. In our approach, we must consider flexural resonators as we are using a MEMS-based approach with AlN as the piezoelectrical material. We will analyze this focus depth capability considering a continuous annular ring array in comparison with a multielement annular ring array. Figure 1 top inset shows a conceptual schematic of a single element from a continuous annular ring array (green) and a single element (squared PMUT) that will form a multielement ring array, (blue). Here $2 D, 2 d$, and $l$ are the outer 
diameter, inner diameter, and width of each ring in the annular array; $a$ and $w$ are the side and diagonal of each square PMUT in the multielement array.

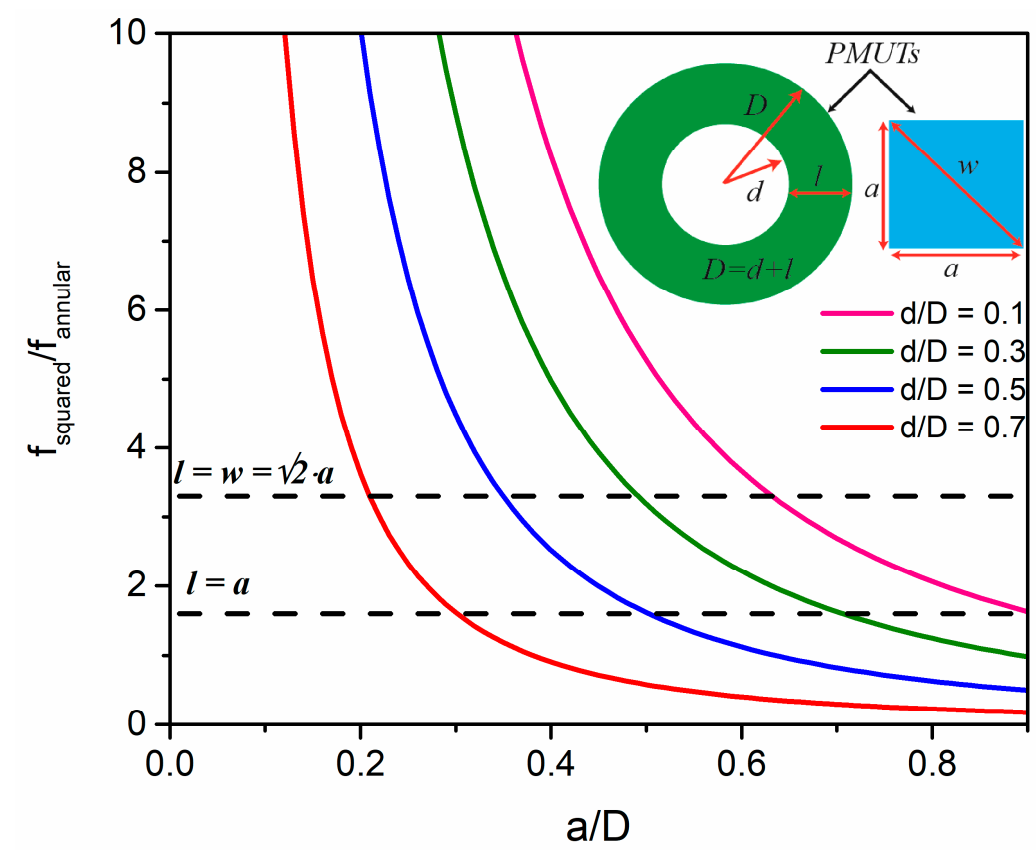

Figure 1. Theoretical frequency ratio, $f_{s} / f_{a}$, from two single elements of an annular array and a multielement multiring array with the same area according to Equation (4). Inset: Only one annular ring and one single square PMUT from the annular and multielement ring arrays are shown.

First, the resonance frequency for the first flexural mode for the annular ring array is giving by Equation (2), where $\lambda_{i j \_a n n u l a r}$ is a dimensionless parameter associated with the vibration mode $(i, j), D_{r}$ is the flexural rigidity, and $\mu$ is the mass per unit area [19]. Intuitively, higher resonance frequencies could be obtained with smaller devices, but the parameter $\lambda_{i j}$ annular is dependent on the ratio of $d / D$ and boundary conditions, so in consequence, the same frequency can be obtained for rings with the same width (no matter how big the outer diameter is), even in the case of flexural resonant rings.

$$
f_{a}=\frac{\lambda_{i j \_a n n u l a r}^{2}}{2 \pi D^{2}} \sqrt{\frac{D_{r}}{\mu}} \quad i=1,2, \ldots j=1,2, \ldots
$$

Second, for a multielement ring array, the resonance frequency is fixed by the individual PMUTs, defined by Equation (3) for the first flexural mode considering square PMUTs [20].

$$
f_{s}=\frac{35.99}{2 \pi a^{2}} \sqrt{\frac{D_{r}}{\mu}}
$$

Using Equations (2) and (3), the ratio $f_{s} / f_{a}$ for the same layer stack is given by Equation (4) and computed in Figure 1 for different $d / D$ ratios considering clamped boundaries where the parameter $\lambda_{i j \_a n n u l a r}{ }^{2}$ has been extracted from Table 11-2 in [19]. The multielement ring array achieves frequencies higher than the annular array when the PMUT side is much smaller than $D$. Dotted lines show the case when the ring width is equal to $a$ (minimum side of the squared PMUT) or $w$, giving for all $d / D$ ratios an improvement in multielement multiring frequency of $1.6 \times$ or $3.3 \times$, respectively. This increase in the resonance frequency is translated into a higher focal length.

$$
f_{s} / f_{a}=\frac{35.99}{(a / D)^{2} \times \lambda_{i j \_a n n u l a r}{ }^{2}} \quad i=1,2, \ldots j=1,2, \ldots
$$


Figure 2a shows an optical image of the proposed multielement ring array ultrasound transducer. The PMUTs are arranged in irregular polygons that are connected through the top electrode forming five concentric channels. The bottom electrode is common for all PMUT devices, and the gap between consecutive elements is $25 \mu \mathrm{m}$.

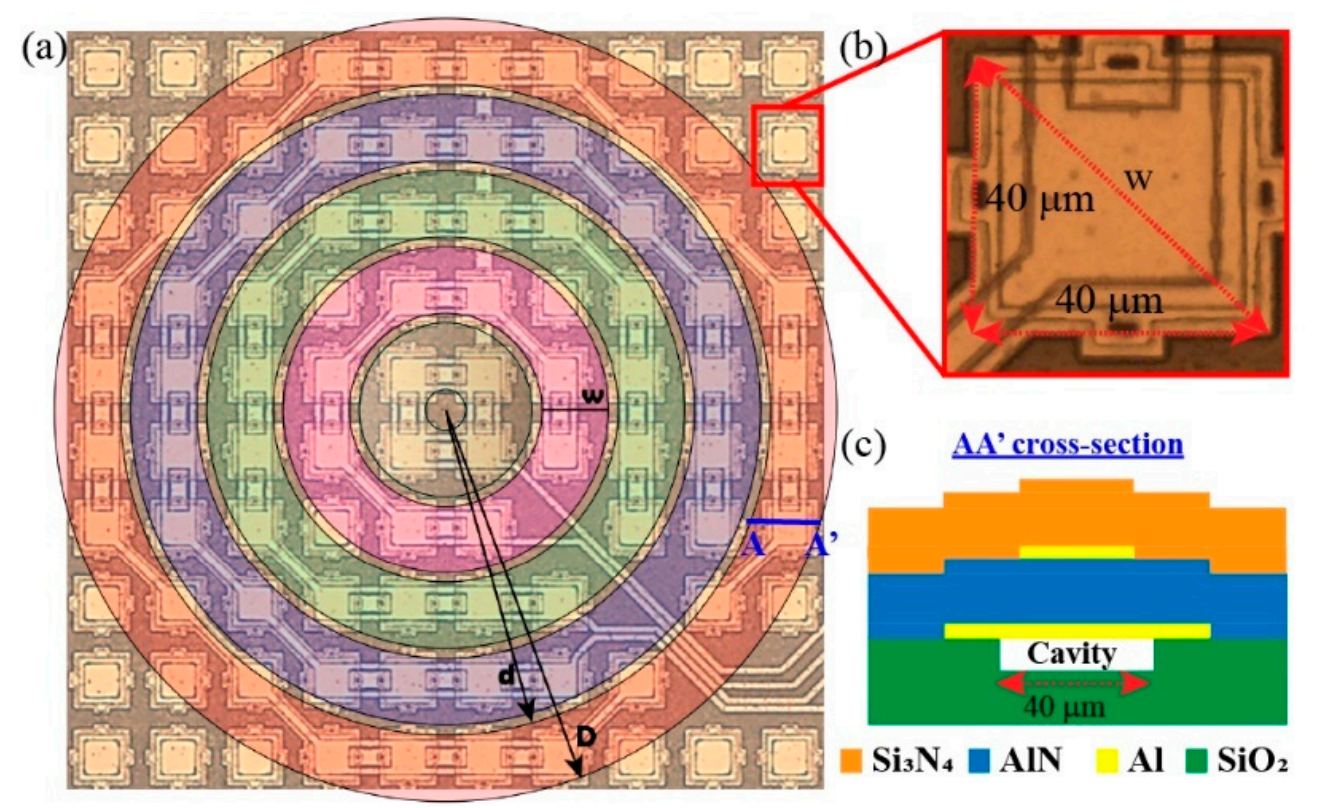

Figure 2. (a) Optical image of the multielement ring array transducer and schematic representation of the continuous rings over it; (b) zoom of the individual $40 \mu \mathrm{m}$ AIN PMUT; (c) AA' cross-section of AIN-PMUT.

Every single element consists of a squared AlN-PMUT with a $40 \mu \mathrm{m}$ side, fabricated using the MEMS-on-CMOS SilTerra technology [16,21]. The top electrode size was optimized to maximize the membrane velocity and consequently the output pressure. A $1.3 \mu \mathrm{m}$ AlN piezoelectric material was deposited by physical vapor deposition (PVD) and sandwiched between two Al electrodes $(0.35 \mu \mathrm{m}$ thickness top electrode and $0.4 \mu \mathrm{m}$ thickness bottom electrode). A $1.5 \mu \mathrm{m} \mathrm{Si}{ }_{3} \mathrm{~N}_{4}$ layer was deposited with a low-temperature plasma-enhanced chemical vapor deposition (PECVD) process; it acts as the elastic layer and seals the cavity. Figure $2 \mathrm{c}$ shows a cross-section profile (AA') of the square PMUT device, and Table 1 summarizes the material properties used in FEM COMSOL simulations and the principal geometric dimensions.

Table 1. Material properties and thickness used in FEM simulations.

\begin{tabular}{cccccc}
\hline \multirow{2}{*}{ PMUT Layer } & \multicolumn{2}{c}{ Properties } & \multicolumn{2}{c}{ Geometric } \\
\cline { 2 - 6 } & Mat. & Young's Modulus $\mathbf{( G P a )}$ & Density $\left(\mathbf{k g} / \mathbf{m}^{\mathbf{3}}\right)$ & Side $(\boldsymbol{\mu m})$ & Thick. $(\boldsymbol{\mu m})$ \\
\hline Substrate & $\mathrm{SiO}_{2}$ & 70 & 2200 & 60 & 2 \\
Bottom Elec. & $\mathrm{Al}$ & 70 & 2700 & 46 & 0.4 \\
Piezoelectric & $\mathrm{AlN}^{1}$ & 279 & 3230 & 60 & 1.3 \\
Top Elec. & $\mathrm{Al}$ & 70 & 2700 & 28.3 & 0.35 \\
Passive & $\mathrm{Si}_{3} \mathrm{~N}_{4}$ & 250 & 3100 & 60 & 1.5 \\
\hline
\end{tabular}

${ }_{1}^{1}$ The piezoelectric coefficients $\mathrm{e}_{33}$ and $\mathrm{e}_{31}$ used in COMSOL are $1.55 \mathrm{C} / \mathrm{m}^{2}$ and $-0.6 \mathrm{C} / \mathrm{m}^{2}$ respectively.

The first mode shape and its resonance frequency for a square $40 \mu \mathrm{m}$ AlN PMUT were obtained in COMSOL Multiphysics; the value of $27.7 \mathrm{MHz}$ was given, which is close to the value computed using Equation (3), $27.8 \mathrm{MHz}$. Dynamic simulations in a liquid environment (Fluorinert, FC-70, with a density $\rho=1940 \mathrm{~kg} / \mathrm{m}^{3}$ and the sound velocity $\mathrm{c}=685 \mathrm{~m} / \mathrm{s}$ ) give a maximum displacement at $13 \mathrm{MHz}$. 
In order to compare the performance of this multielement ring array transducer with an equivalent continuous concentric ring, we considered the circles that surround the single-PMUT elements. The shape of each ring is close to an irregular polygon, and it is not possible to obtain rings that include all PMUTs of the polygon exactly. Figure 2a shows in different colors the geometric representation corresponding to each continuous ring, where $D$ and $d$ are the outer and the inner radii, respectively, and $w$ is the width. The values of $D$ and $d$ were computed trying to include the highest number of PMUTs of each irregular polygon into the continuous ring. The width, $w$, corresponds to the PMUT diagonal (the furthest PMUT point inscribed in the continuous ring) and is $56.6 \mu \mathrm{m}\left(\sqrt{ }(40 \mu \mathrm{m})^{2}+(40 \mu \mathrm{m})^{2}\right)$ (see Figure 2b). A gap of $8.4 \mu \mathrm{m}$ between rings is obtained. Decreasing the ring width to $w=a$, higher resonance frequency for the continuous ring can be achieved at the expense of not including the largest number of PMUTs within it. Table 2 summarizes the computed dimensions taking into account all these considerations.

Table 2. Focus depth comparing multielement ring array with an equivalent continuous ring array using Equation (1) and the resonance frequencies obtained from the COMSOL simulations. The $F_{d}$ is calculated with all actuated smaller rings. $(c=685 \mathrm{~m} / \mathrm{s})$.

\begin{tabular}{ccccc}
\hline \multirow{2}{*}{ Number of Rings } & \multicolumn{2}{c}{ Dimensions } & \multicolumn{2}{c}{ Focal Point $\rightarrow$ Fd $(\mu \mathrm{m})$} \\
\cline { 2 - 4 } & $\mathbf{D}(\mu \mathrm{m})$ & $\mathbf{d}(\boldsymbol{\mu m})$ & $\begin{array}{c}\text { Continuous Ring; } \\
\mathbf{f}=\mathbf{2 . 3} \mathbf{~ M H z}\end{array}$ & $\begin{array}{c}\text { Multielement Ring; } \\
\mathbf{f}=\mathbf{1 1 . 3} \mathbf{~ M H z}\end{array}$ \\
\hline 1 & 74.28 & 17.68 & 13.7 & 67.4 \\
2 & 139.28 & 82.68 & 50.3 & 247.3 \\
3 & 204.28 & 147.68 & 109.2 & 536.6 \\
4 & 269.28 & 212.68 & 190.4 & 935.4 \\
5 & 334.28 & 277.68 & 293.8 & 1444 \\
\hline
\end{tabular}

As the parameter $\lambda i j$ in Equation (2) and the added virtual mass are only known for defined $d / D$ ratios $[19,22]$, we performed some FEM simulations with COMSOL to find the resonance frequencies for the first continuous ring in air and liquid, obtaining 8.9 and $2.3 \mathrm{MHz}$ respectively. The resonance frequency for the continuous ring is 3 times lower than that of the multielement ring $(27.8 / 8.9)$, which is close to the $f_{\text {squared }} / f_{\text {annular }}$ ratio when the annular width corresponds to the square PMUT diagonal (see Figure 1 when $l=w$ ). Figure 3 shows the frequency response in liquid for the first ring corresponding to the continuous ring and the multielement ring array. The normalized pressure maps for both rings, considering a propagation medium of $200 \mu \mathrm{m}$ radius, are shown in Figure $3 b, c$. The multielement array achieves a higher focus depth in comparison to a continuous ring (considering the same actuated rings) due to its higher operation frequency (see $F_{d}$ in Table 2), concentrating the acoustic pressure in a narrower beam, but it is affected by side lobes. The focus depth $\left(F_{d}\right)$ is presented in Table 2 for both the multielement ring array device and the continuous concentric ring device considering the same area in both cases. The advantage of focus depth control for the multielement ring array from $67 \mu \mathrm{m}$ to $1.44 \mathrm{~mm}$ is clearly demonstrated. 


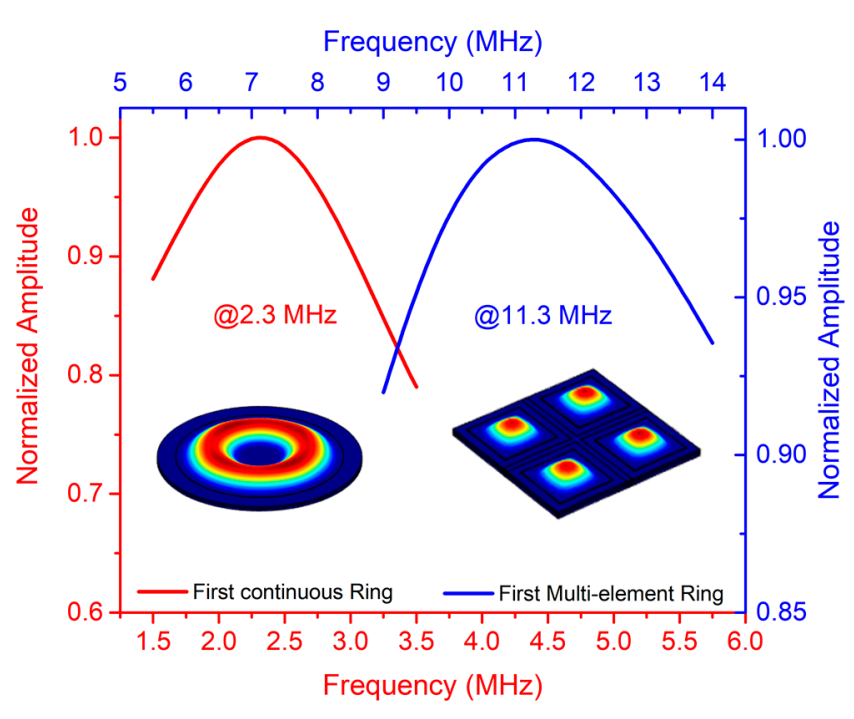

(a)

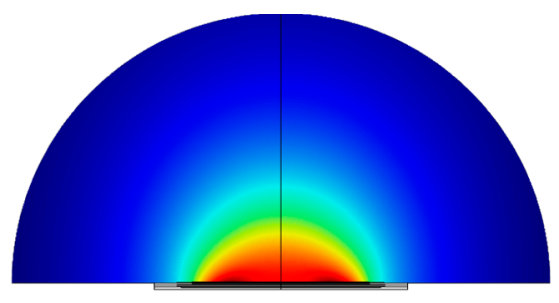

(b)

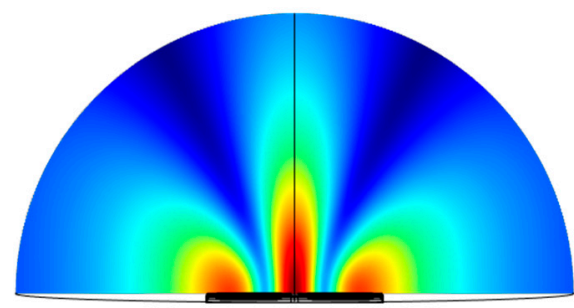

(c)

Figure 3. FEM COMSOL dynamic simulation in liquid for the first continuous ring and the first multielement ring: (a) frequency response where left-bottom (red curve) corresponds to continuous ring and right-top (blue curve) corresponds to multielement ring; (b) continuous ring pressure map at $2.3 \mathrm{MHz}$; (c) multielement ring pressure map at $11.3 \mathrm{MHz}$.

\subsection{Acoustic Performance Simulation for the PMUT Array}

Acoustic simulations using Field II $[23,24]$ were performed to predict the acoustic performance of the multielement ring array working in liquid (FC-70, c = $685 \mathrm{~m} / \mathrm{s}$ ) at a center frequency of $11.3 \mathrm{MHz}$ (according to the FEM COMSOL simulations shown in Figure 3).

Figure 4 shows the 2D normalized pressure map from $20 \mu \mathrm{m}$ to $3 \mathrm{~mm}$ along the axial direction and from $-500 \mu \mathrm{m}$ to $500 \mu \mathrm{m}$ laterally, keeping the array center at $(0,0)$ coordinates. Note that, as Table 2 shows, by playing with the number of active rings, the focal point can be changed without any extra delay. The beam focusing range from these Field II simulations is a bit higher, reaching $1.6 \mathrm{~mm}$, due to the simulation considering the real element distribution inside the multielement ring array (gap spaces between elements), which is small and is not considered in Equation (1).

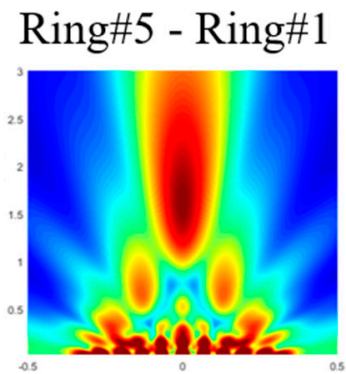

(a)

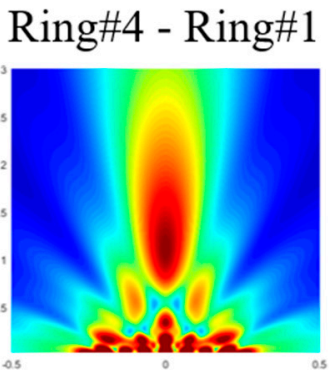

(b)

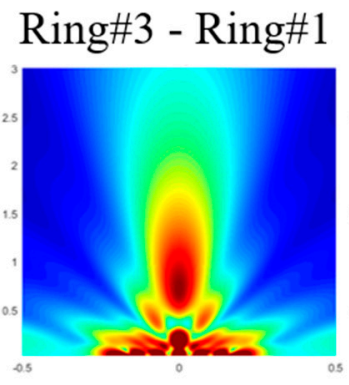

(c)

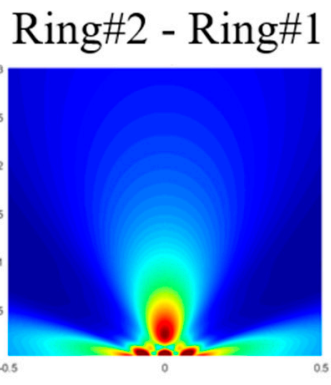

(d)

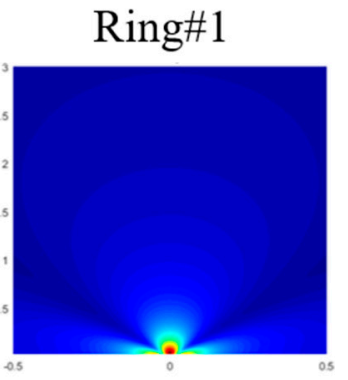

(e)

Figure 4. Field II simulated pressure map for the multielement array when transmitting with (a) all rings, (b) four rings (ring \#1 to ring \#4), (c) three rings (ring \#1 to ring \#3), (d) two rings (ring \#1 to ring \#2), and (e) one ring (ring \#1). Axis: Scan in $\mathrm{x}$-direction from -0.5 to $0.5 \mathrm{~mm}$, z-direction from 0.02 to $3 \mathrm{~mm}$.

On the other hand, controlling the applied signal phase, the focal point can also be modified (electronic focusing), achieving higher pressure levels than at the natural focus. In Figure 5a, the red axis shows the dependence of the transmission improvement on the acoustic focusing factor $(S a c)$, defined as $S a c=F a c / N_{0}$ where $F a c$ is the actual focus and 
$N_{0}$ is the natural focus (1.6 mm). In the simulations, the delays were applied to all the elements that make up each ring. As expected, when the focus point is close to natural focus, there is no transmission sensitivity enhancement (value close to 1 ), so to ensure at least twice as much the transmission pressure, the acoustic focusing factor should be 0.8 (and consequently the focal point will be $1.3 \mathrm{~mm}$ ). Furthermore, when it is focused, the acoustic energy is concentrated in narrow beams, decreasing the focus width, and consequently improving the capability to detect small targets. On the other hand, in Figure $5 \mathrm{a}$, the blue axis shows the dependence of the beamwidth at $-6 \mathrm{~dB}$ on the acoustic focusing factor. In this case, the beamwidth is wider when the acoustic focusing factor is close to 1 , as expected.

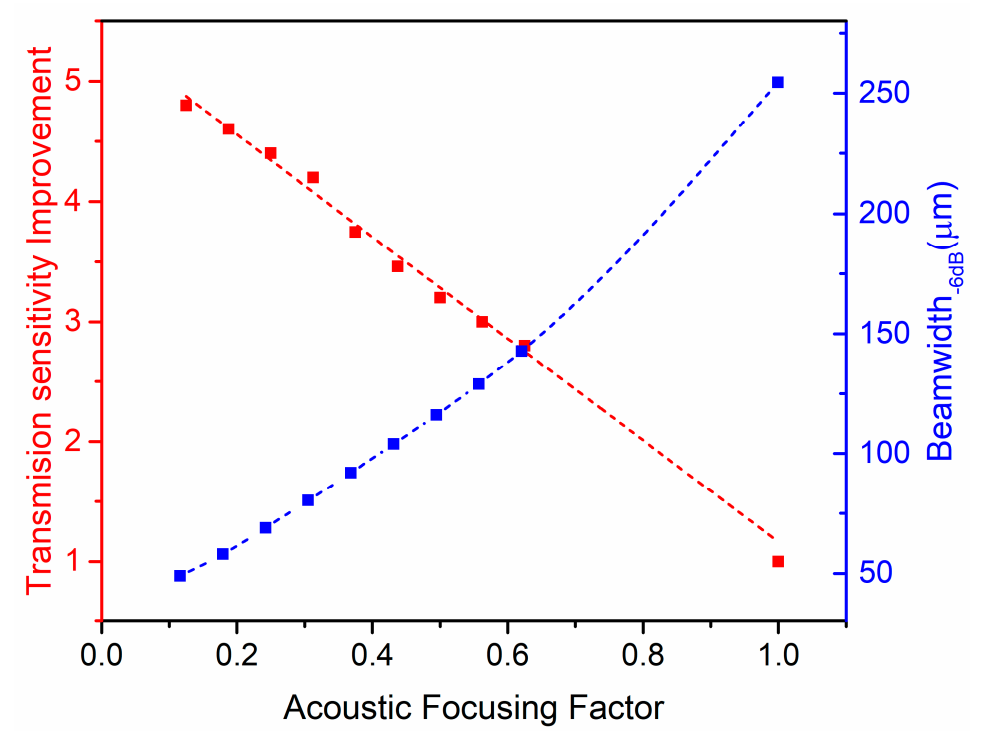

(a)

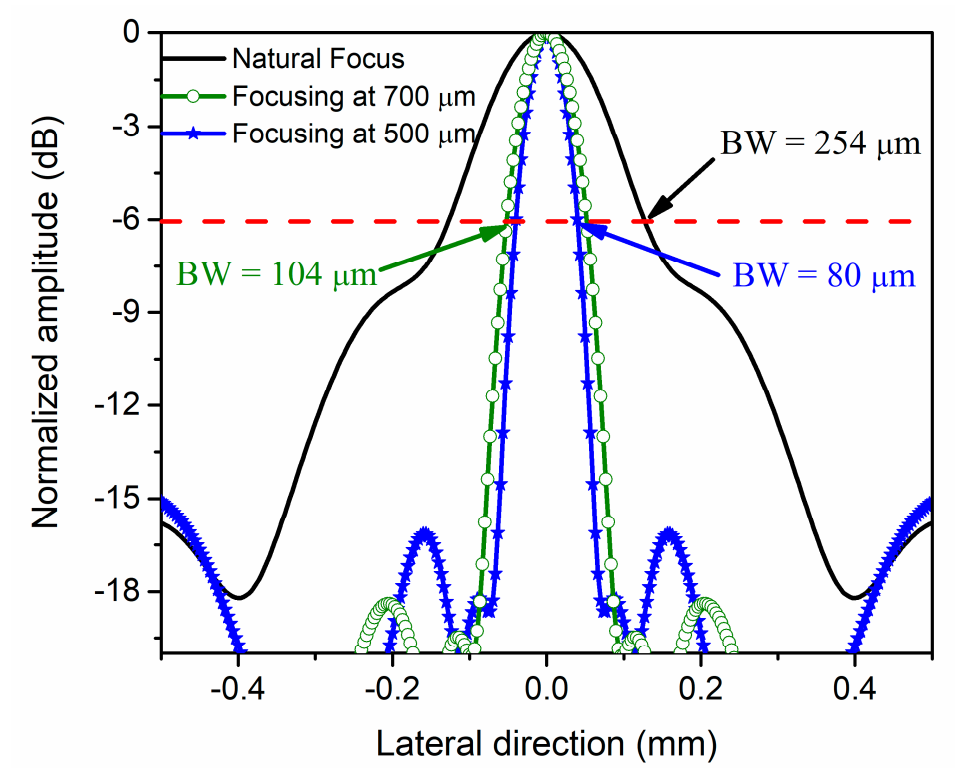

(b)

Figure 5. Field II simulations: (a) dependence of the transmission sensitivity improving factor (red curve) and the beamwidth (blue curve) on the acoustic focusing factor; (b) cross-section in lateral direction at two different focal points (500 and $700 \mu \mathrm{m}$, corresponding to acoustic focusing factors of 0.3 and 0.44 , respectively). 
Figure $5 \mathrm{~b}$ shows the acoustic pressure field profile along the lateral direction at different focus points, including the natural focus $\left(N_{0}\right)$. As can be seen, the multielement ring array is affected by the generation of unwanted lobes (side lobes). For focus depths greater than $500 \mu \mathrm{m}$, these side lobes are below $-15 \mathrm{~dB}$, which is proven to be the required dynamic range for imaging [25].

\section{Experimental Results and Discussion}

\subsection{Electrical Characterization}

The electrical characterization in the air was done using the multiring PMUTs bonded to a PCB and using a network analyzer (Agilent Technologies, Santa Clara, CA, USA). Figure 6a left inset shows a schematic of the experimental set-up. Each ring was powered with $10 \mathrm{dBm}$ continuous wave to obtain the S-parameters. The frequency response, $S_{11}$, for each ring, gives a center value of $17.5 \mathrm{MHz}$, which corresponds to the resonance frequency of an individual PMUT (single clamped square PMUT, as reported in [26]).

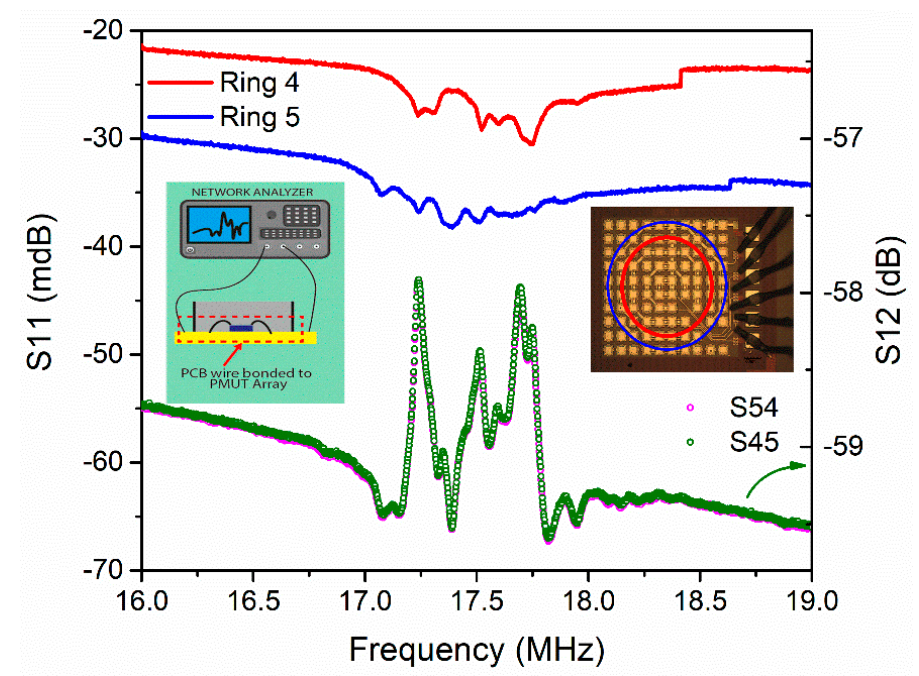

(a)

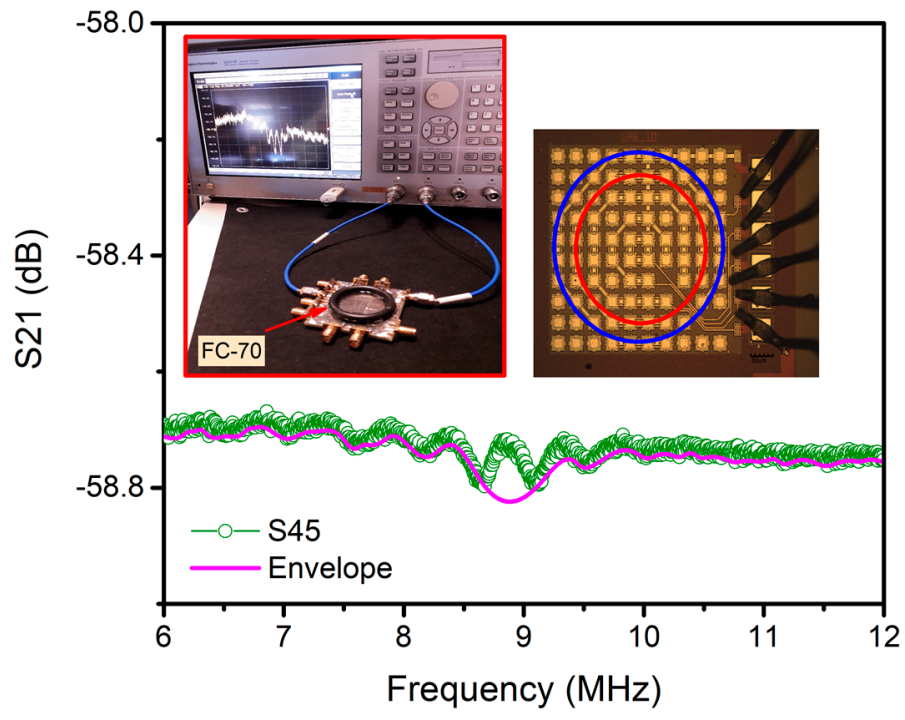

(b)

Figure 6. Scattering parameter measurements $(a)$ in air $\left(S_{11}\right.$, red and blue curves with left axis; $S_{12}$, green and rose curves with right axis) using rings $\# 4$ and $\# 5$ and (b) in Fluorinert, $S_{12}$ using rings $\# 4$ and \#5. 
In Figure 6a, the red curve shows the frequency response corresponding to ring \#4, and the blue curve shows the ring \#5 response. The multiple peaks are a consequence of the multiple individual PMUTs forming the ring.

In order to analyze the electrical crosstalk effect in the proposed device, the $S_{21}$ magnitude between pairs of rings was obtained [27]. In Figure 6a, the dotted graph (green curve) corresponds to the measurements between ring \#5 and ring \#4. The crosstalk level was obtained considering the $S_{21}$ at $19 \mathrm{MHz}$ (out of the resonance peak), giving for this case $-59.4 \mathrm{~dB}$ which represents $2.1 \mathrm{mVpp}$ (for a $10 \mathrm{dBm}$ input signal). Even if the crosstalk level during the resonance is considered, there would be no significant actuation voltage in the non-actuated rings, decreasing the risk of acoustic interferences. Table 3 summarizes the obtained crosstalk between rings. Note that the lowest level, $-77 \mathrm{~dB}$, is between ring \#1 and ring \#4 and not between the most widely spaced rings (ring \#1 and ring \#5). This can be attributed to the specific layout of the electrical pads (consecutive pads for rings \#1 and \#5). The low crosstalk levels (below $-56.8 \mathrm{~dB}$ ) between multielement rings will allow driving each ring independently, ensuring a well-controlled and efficient axial beam-focusing.

Table 3. Crosstalk between rings, according to $\mathrm{S} 21$ experimental magnitude at $19 \mathrm{MHz}$ in air.

\begin{tabular}{cccccc}
\hline dB & $\mathbf{1}$ & $\mathbf{2}$ & $\mathbf{3}$ & $\mathbf{4}$ & $\mathbf{5}$ \\
\hline 1 & $\times$ & -56.8 & -76 & -77 & -70 \\
2 & & $\times$ & -69.5 & -74 & -72.5 \\
3 & & & -62 & -69.5 \\
4 & & & $\times$ & -59.4 \\
5 & & & & $\times$ \\
\hline
\end{tabular}

The variation of resonance frequencies for each of the individual resonators due to mismatching during the fabrication can be a drawback. This problem can be alleviated when the system is under liquid operation due to the acoustic radiation mass loading effect from the liquid which widens the resonance frequency curve. For a square PMUT transducer under liquid operation in one side, this mass load damping can be quantified according to Equation (5) (where $\rho_{\text {liquid }}$ is the liquid density, $a$ is the transducer side, and $\mu$ is the mass per unit area) [28], which gives $\beta=2.46$.

$$
\beta=0.342 \frac{\rho_{\text {liquid }} \times a}{\mu}
$$

Then, the expected resonance frequency in liquid will be approximately half the air resonance frequency, i.e., $9.4 \mathrm{MHz}($ fair $/ \sqrt{ }(1+\beta))$. Figure $6 \mathrm{~b}$ shows the electrical frequency response of the crosstalk between ring \#5 and ring \#4 in FC-70. The resonance peaks appear between 8 and $10 \mathrm{MHz}$, being in correspondence with the expected value $(9.4 \mathrm{MHz})$. On the other hand, in liquid, the high acoustic radiation damping is translated into a low quality factor and consequently to higher fractional bandwidth, hence lowering the $S_{21}$ magnitude at resonance and smoothing the single-element frequency peaks of the same ring.

\subsection{Output Pressure Measurements}

The multielement ring array was immersed in Fluorinert $\left(\mathrm{c}=685 \mathrm{~m} / \mathrm{s}, \rho=1940 \mathrm{~kg} / \mathrm{m}^{3}\right)$ and each ring was driven by a signal generator (Keysight, Santa Rosa, CA, USA) with four sine cycles with $24 \mathrm{Vpp}$. The acoustic pressure was measured with a commercial hydrophone from ONDA (Santa Clara, CA, USA) and displayed in an oscilloscope (Santa Rosa, CA, USA); Figure 7 shows the set-up. The experimental resonance frequency (tuned to maximize hydrophone signal) was $8.7 \mathrm{MHz}$ in accordance with the electrical measurements. 


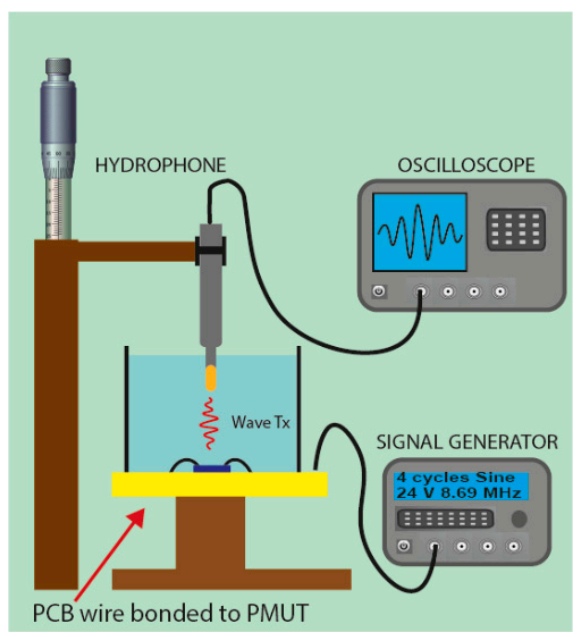

(a)

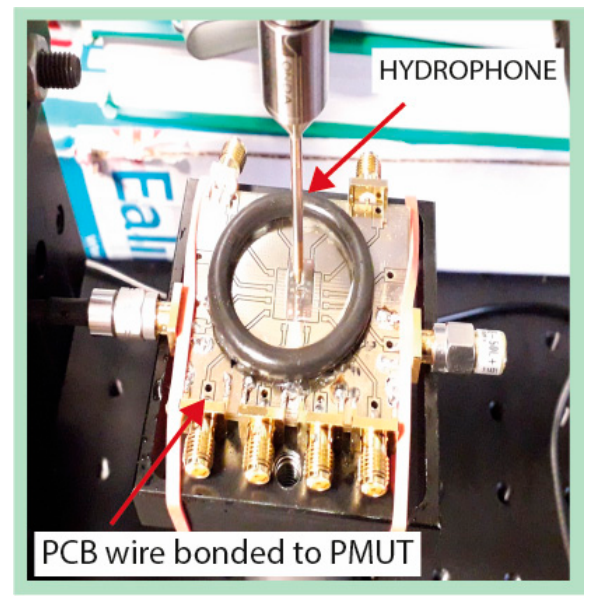

(b)

Figure 7. Set-up for the acoustic characterization as actuator in liquid environment (a) schematic set-up and (b) photo of the experimental set-up.

In order to avoid artifacts on the pressure field characterization due to spatial averaging effects (consequence of the influence of the hydrophone's diameter), there is a limitation on the minimum axial distance between the hydrophone and the ultrasound transducer. Equation (6) should be used [29] to estimate the maximum effective hydrophone radius $\left(a_{h}\right)$, taking into account the transducer radius $\left(a_{1}\right)$, the wavelength in the acoustic media $(\lambda=c / f)$, and the distance between the hydrophone and the transducer $(l)$. In our experimental set-up, $a_{h}=100 \mu \mathrm{m}$ (HNC-0200 radius), $c=685 \mathrm{~m} / \mathrm{s}$, and $f=8.69 \mathrm{MHz}$, giving the ratio $l / 2 a_{1}=5.06$, which means different minimum distances depending on the ring size; Table 4 summarizes these values for all cases (Lmin represents $l$ in Equation (6)).

$$
a_{h}=\frac{\lambda}{8 a_{1}}\left(\sqrt{l^{2}+a_{1}^{2}}\right)
$$

Therefore, in the experiments, the hydrophone was placed at the distances detailed in Table 4 and raised every $50 \mu \mathrm{m}$ to obtain the axial pressure at different heights without distortion. These distances are in the far-field, which allows defining the acoustic pressure by Equation (7) [18] (where $R_{0}$ is the Rayleigh distance, $P_{0}$ is the surface pressure, and $z$ is the axial distance).

$$
P(z)=\frac{P_{0} R_{0}}{z}
$$

Table 4. Individual ring characterization as actuator in FC-70 using HNC-0200 from ONDA (at

\begin{tabular}{|c|c|c|c|}
\hline Ring & $\operatorname{Lmin}(\mathrm{mm})$ & $N P(\mathbf{k P a} \times \mathbf{m m})$ & $\begin{array}{c}\text { Pressure }(\mathrm{kPa}) \\
\text { at } 1.2 \mathrm{~mm}\end{array}$ \\
\hline 1 & 0.531 & 6.33 & 5.28 \\
\hline 2 & 1.19 & 10.04 & 8.37 \\
\hline 3 & 1.84 & 14.92 & 12.43 \\
\hline 4 & 2.2 & 15.41 & 12.84 \\
\hline 5 & 3.16 & 14.2 & 11.79 \\
\hline
\end{tabular}
$8.69 \mathrm{MHz}$ ). Lmin is computed from Equation (6); NP is experimentally measured.

The measured points were fitted according to Equation (7), obtaining from the slope the normalized pressure with the distance $N P=P_{0} R_{0}(\mathrm{~Pa} \times \mathrm{mm})$ for each ring (see the results in Table 4 ). From these measurements, the maximum attainable pressure at the natural focus ( $1.2 \mathrm{~mm}$ according to Field II simulations at $8.69 \mathrm{MHz})$ can be computed, 
evaluating the NP for each ring at $1.2 \mathrm{~mm}$ and adding them because, at this point, all acoustic waves are in phase, allowing constructive interference. Finally, the computed total pressure is $50.71 \mathrm{kPa}_{\mathrm{pp}}$. This output pressure could be increased until 4.8 times, for example, focusing at $200 \mu \mathrm{m}$ (see the improvement factor in Figure 5a).

The normalized acoustic pressure (ST) at $1.5 \mathrm{~mm}$ from a $1 \mathrm{~mm}^{2}$ PMUT array area when it is driven with $1 \mathrm{~V}$ was used to compare the multielement ring array with other ultrasound transducers. Taking the previously computed pressure when all rings are excited, $50.71 \mathrm{kPa}_{\mathrm{pp}}$, and normalizing with the distance $(1.2 \mathrm{~mm})$ and the applied voltage (24 Vpp), we obtain a surface pressure of $2.54 \mathrm{kPa}_{\mathrm{pp}} \times \mathrm{mm} \times \mathrm{V}^{-1}$. According to this and considering the entire area of the multielement ring array $\left(\pi \times\left(\mathrm{D}_{5}{ }^{2}-\mathrm{d}_{1}{ }^{2}\right)=0.35 \mathrm{~mm}^{2}\right)$, the normalized pressure at $1.5 \mathrm{~mm}$ is $4.84 \mathrm{kPa} / \mathrm{V} / \mathrm{mm}^{2}$. Table 5 compares the multielement ring array performance as an actuator with the state-of-the-art approaches, demonstrating a promising performance with a minute area. The normalized output pressure is $55 \%$ higher than that reported for arrays of annular AlN flexural rings $\left(2.2 \mathrm{kPa} / \mathrm{V} / \mathrm{mm}^{2}\right.$ using fivechannel ring [6]) and even 92\% higher than that for a system for intravascular imaging [2].

Table 5. Comparison of ring arrays with different technological approaches.

\begin{tabular}{|c|c|c|c|c|}
\hline \multirow{2}{*}{ Parameters } & [30] & [2] & [6] & \multirow{2}{*}{ This Work } \\
\hline & 2011 & 2018 & 2019 & \\
\hline $\begin{array}{l}\text { Transducer } \\
\text { technology }\end{array}$ & CMUT & PZT matrix & AlN PMUT & AlN PMUT \\
\hline Configuration & Multielement ring & Multielement ring & Continuous ring & Multielement ring \\
\hline Medium & Vegetable oil & Water & Mineral oil & FC-70 \\
\hline Frequency (MHz) & 1.2 & 14 & 6 & 8.69 \\
\hline Area $\left(\mathrm{mm}^{2}\right)$ & $12.76^{1}$ & $6.28^{1}$ & $7.07^{1}$ & 0.35 \\
\hline Pressure & 13.2 & 0.4 & 2.8 & 2.11 \\
\hline (kPa/V@mm) & $@ 1.5^{2}$ & @6 & $@ 5.4$ & $@ 1.2$ \\
\hline $\mathrm{NP}(\mathrm{kPa} \times \mathrm{mm} / \mathrm{V})$ & 19.8 & 2.4 & 15.2 & 2.54 \\
\hline $\mathrm{ST}\left(\mathrm{kPa} / \mathrm{V} / \mathrm{mm}^{2}\right)$ & $1.11^{3}$ & $0.38^{3}$ & $2.18^{3}$ & 4.84 \\
\hline
\end{tabular}

${ }^{1}$ Computed considering the transducers' dimensions. ${ }^{2}$ Taking the peak-to-peak pressure $(2 \times 66 \mathrm{kPa})$ and the applied voltage $(10 \mathrm{~V}) \cdot{ }^{3}$ Computing as the ratio between NP evaluated at $1.5 \mathrm{~mm}$ and the area.

In order to complete a deeper characterization of the performance of the system as an actuator and compare the presented multielement array system with a continuous AlN flexural PMUT array [6], the pressure normalized with the area and energy density, $(\bar{p})$, defined in Equation (8) was computed (where $V$ is the applied voltage $(24 \mathrm{~V}), A_{a p}$ is the area $\left(0.35 \mathrm{~mm}^{2}\right), e_{31, f}$ is the piezoelectric coefficient $\left(e_{31, f}=e_{31}-v \times e_{33}=-1.065 \mathrm{C} / \mathrm{m}^{2}\right), \lambda$ is the wavelength $(\lambda=c / f=79.86 \mu \mathrm{m})$, and $p$ is the total pressure $(50.71 \mathrm{kPa}$ at $1.2 \mathrm{~mm})$ ).

$$
\bar{p}=p \times \frac{\lambda}{V \times A_{a p} \times e_{31, f}}
$$

Applying this expression at $1.2 \mathrm{~mm}$ (the natural focus) when the multielement five-ring array is used, a normalized pressure per area per energy density of $453 \mathrm{kPa} \times \mathrm{mm}^{-2} / \mathrm{J}^{\circ} \mathrm{cm}^{-3}$ is obtained, which is $2.5 \times$ better than that of the five-channel continuous ring array without delays presented in [6] $\left(184 \mathrm{kPa} \times \mathrm{mm}^{-2} / \mathrm{J} \times \mathrm{cm}^{-3}\right)$. Compared with the result when the same system is focused at $1.9 \mathrm{~mm}\left(588 \mathrm{kPa} \times \mathrm{mm}^{-2} / \mathrm{J} \times \mathrm{cm}^{-3},[6]\right)$, our multielement ring array still exhibits a competitive value and will allow higher pressure output at shorter focus depths if some phase-beam focusing is used.

\subsection{Pulse-Echo Measurements}

Thanks to its reduced area, the multielement ring array can be a candidate for catheterbased ultrasound imaging; consequently, it was also characterized as a pulse-echo acoustic system. In this case, the central ring was used as a receiver, and the rings \#5, \#4, and \#3 were used as transmitters. The same signal generator was used to drive the transmission with four sine cycles at $8.69 \mathrm{MHz}$ with $24 \mathrm{Vpp}$. The receiving ring was externally connected 
to an integrated CMOS voltage amplifier with a gain of $25 \mathrm{~dB}$ [31]. The liquid thickness over the PMUT chip was tuned to obtain different times of flight (ToFs) and consequently different acoustic paths $(A P=T o F \times c)$ giving a round trip from 1 to $5 \mathrm{~mm}$; Figure 8 shows the set-up.

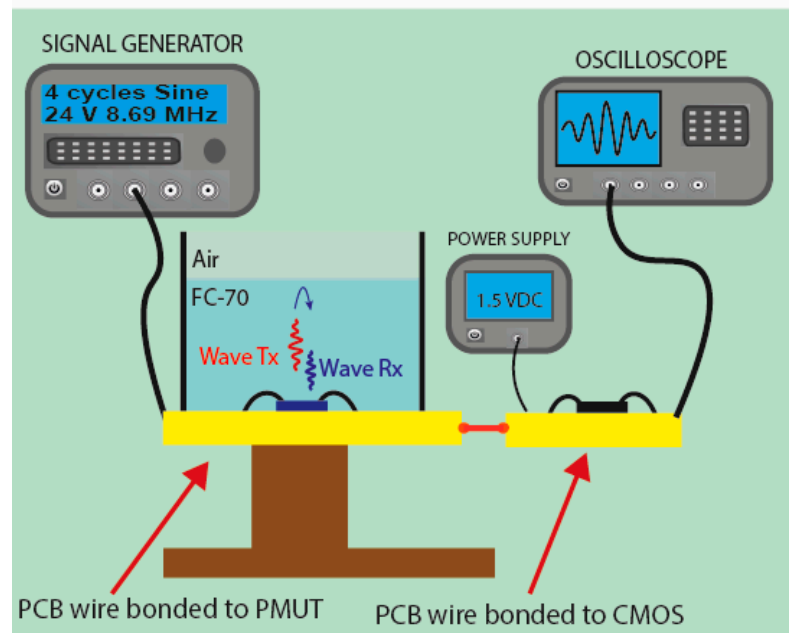

(a)

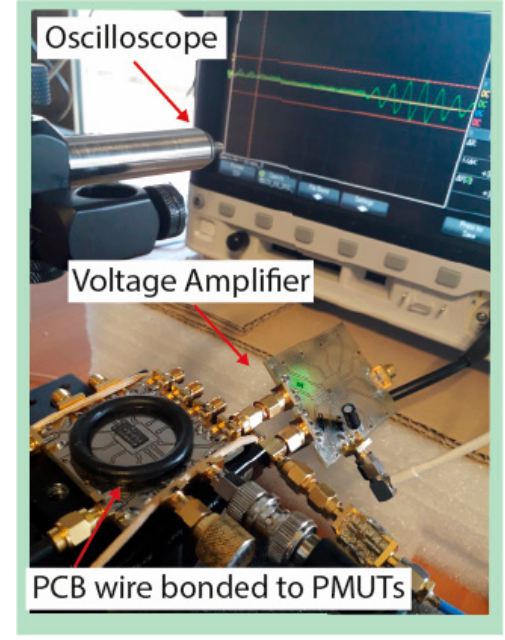

(b)

Figure 8. (a) Schematic set-up for pulse-echo measurements; (b) photo of the experimental set-up.

Figure 9 shows the measured echo voltage and its dependence on the acoustic path using ring \#3 (blue points) (same measurements were also acquired for ring \#4 and ring \#5). Taking the fitting results, the receiving sensitivity (SR) can be computed as $R x / P t$ (where $P t$ is defined by the normalized pressure, NP/z, in Table 4), giving an average value of $441.6 \mathrm{nV} / \mathrm{Pa}\left(\left(\mathrm{Rx}_{\text {central }} / \mathrm{Pt}_{3}+\mathrm{Rx}_{\text {central }} / \mathrm{Pt}_{4}+\mathrm{Rx}_{\text {central }} / \mathrm{Pt}_{5}\right) / 3\right)$. This receiving sensitivity is affected by the parasitic capacitances between the PMUT and voltage amplifier (PCB, connectors, cables, etc.) according to Equation (9) [32]:

$$
S R=S R_{E O C} \times G \times \frac{C_{\text {centralRing }}}{C_{\text {centralRing }}+C_{\text {inLNA }}+C_{\text {parasitic }}}
$$

where $S R_{E O C}$ is the "end-of-cable open-circuit sensitivity"; $G$ is the amplifier gain $(25 \mathrm{~dB})$; $C_{\text {centralRing }}$ is the receiving element capacitance ( $254.9 \mathrm{fF}$ extracted from COMSOL); $C_{\text {inLNA }}$ is the voltage amplifier equivalent capacitance $(609 \mathrm{fF})[16]$; and $C_{\text {parasitic }}$ is the parasitic capacitance associated with PCBs, connectors, cables, etc. (at $6.5 \mathrm{pF}$ ). Hence, the intrinsic sensitivity $\left(S R_{E O C}\right)$ for the smaller inner ring is $717.8 \mathrm{nV} / \mathrm{Pa}$. This value is very competitive in comparison with some commercial hydrophones with sizes comparable to our ring $\# 1$ (diameter of $\sim 149 \mu \mathrm{m}$ ) but with smaller nominal $S R_{E O C}$ pressure sensitivities: HNC0200 from ONDA (200 $\mu \mathrm{m}$ diameter, $\mathrm{SR}_{\mathrm{EOC}}=28 \mathrm{nV} / \mathrm{Pa}$ [32] $)$ or NH0200 from Precision Acoustics $(200 \mu \mathrm{m}, 55 \mathrm{nV} / \mathrm{Pa}$ with amplifier [33]).

The time-domain response shown as the red curve in Figure 10 corresponds to pulseecho measurement when ring \#4 is used to transmit and the central ring is used to receive. The time-of-flight of the received echo is $2.34 \mu \mathrm{s}$, which gives an FC-70 thickness of $800 \mu \mathrm{m}$ $\left(\mathrm{FC70}_{\text {thickness }}=\mathrm{ToF} \times \mathrm{c} / 2\right)$. Taking the ringdown, the fast Fourier transform was computed (see Figure 10, blue curve), giving a resonance frequency $\left(\mathrm{f}_{0}\right)$ of $8.8 \mathrm{MHz}$ with fractional bandwidth at $-6 \mathrm{~dB}$ close to $54 \%$. 


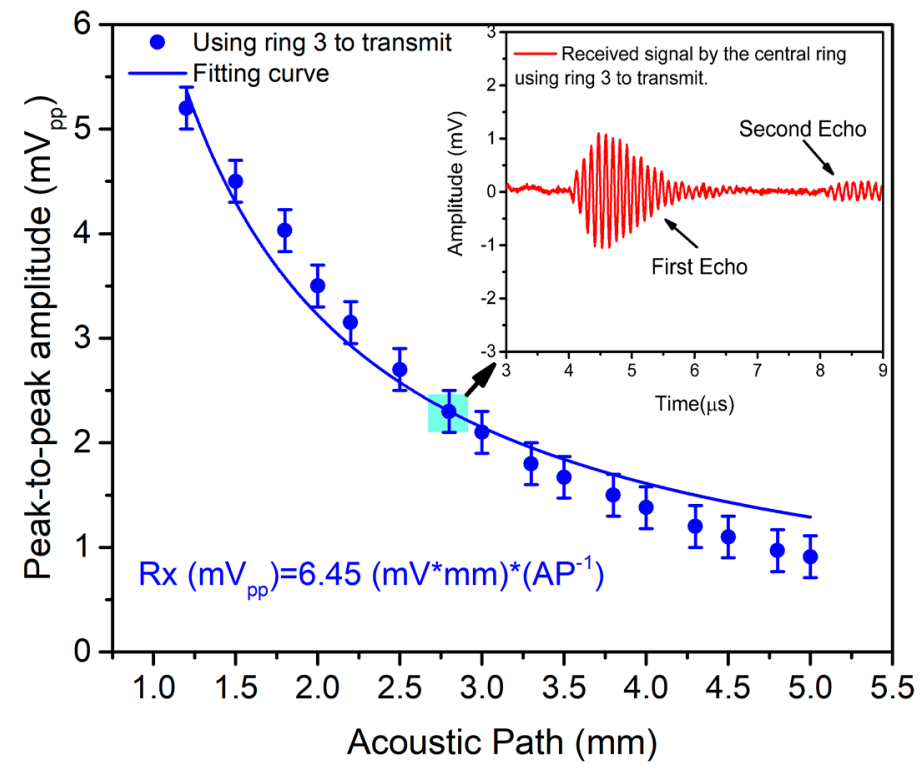

Figure 9. Pulse-echo experiment with ring \#3 as transmitter and ring \#1 as receiver. The received signal is plotted as a function of the acoustic path, $A P$, using FC-70-air interface as reflecting surface. Error bar $= \pm 200 \mu \mathrm{V}$. Inset: Time-domain signal at $2.8 \mathrm{~mm}$ round trip.

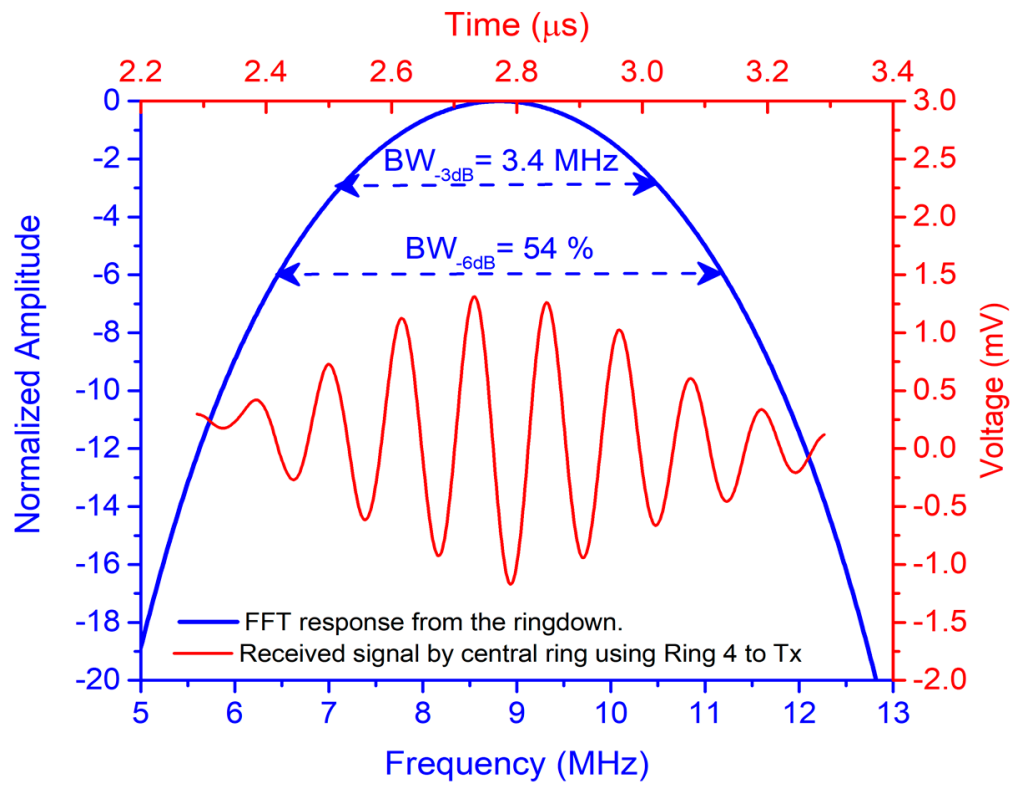

Figure 10. Acoustic pulse-echo measurement using ring \#4 to transmit and central ring to receive (FC-70 thickness at $800 \mu \mathrm{m}$ ). Red curve (top-right red axis): time-domain response. Blue curve (left-bottom blue axis): FFT from the ringdown.

The acoustic beamwidth was determined through a pulse-echo experiment where ring \#3 and ring \#4 were used as transmitters and the central ring was used as the receiver. A $150 \mu \mathrm{m}$ diameter conductive wire was used as a reflecting surface and was placed at $790 \mu \mathrm{m}$ over the array's surface. The wire covered all PMUTs in one lateral direction, and in the other direction, it was mechanically displaced $500 \mu \mathrm{m}$ to each side from the center of the array (see Figure 11 inset). Figure 11 provides experimental and simulation results (using Field II) for when only ring \#3 or ring \#3 + ring \#4 were excited. According to the simulations, the beamwidth at $-6 \mathrm{~dB}$ is around $160 \mu \mathrm{m}$ when ring $\# 3+$ ring $\# 4$ are used (blue lines in Figure 11) and is $180 \mu \mathrm{m}$ when only ring \#3 is used (red lines in Figure 11). 
Moreover, the maximum amplitude increases by about $6 \mathrm{~dB}$ when both rings are used. The experimental points demonstrate a very good agreement with the simulated ones.

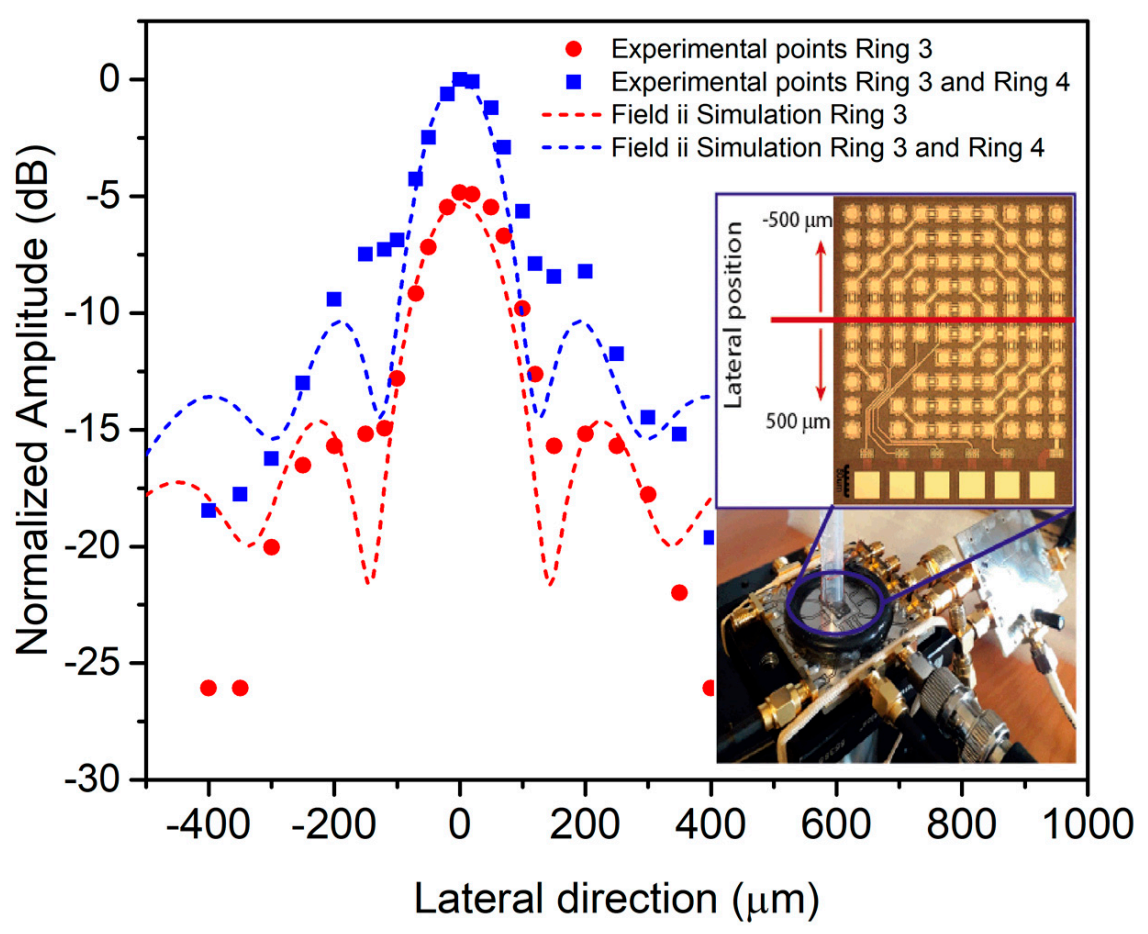

Figure 11. Simulated and experimental behavior along the lateral direction at $790 \mu \mathrm{m}$ axial distance. Red curves correspond to ring \#3 as transmitter and blue curves correspond to ring \#3 + ring \#4 (dots: experimental points; lines: Field II simulations). Inset: Experimental set-up.

\subsection{Focusing Capabilities}

The focusing capabilities were demonstrated through a pulse-echo experiment using ring \#3 and ring \#5 as transmitters and the central ring as a receiver (see set-up in Figure 8). The acoustic path was tuned in the same way, changing the FC-70 thickness and measuring the time-of-flight corresponding to ring \#3 (nearest to receiver element).

Figure 12 (inset) shows the signal received by the central ring when ring \#3 and ring \#5 are used separately. As can be seen, the received acoustic waves from ring \#3 and ring \#5 are not in phase; in consequence, when both rings are driven together, the total acoustic pressure is less than the sum of both echoes. The behavior without any delays is shown in Figure 12 (green points), giving a maximum level of $6.59 \mathrm{mVpp}$ close to $1.5 \mathrm{~mm}$ round trip (natural focus). Considering this value and the computed receiving sensitivity $(441.6 \mathrm{nV} / \mathrm{Pa})$, the pressure on the array's surface is $14.9 \mathrm{kPa}$ pp.

For electronic focusing or phased-array rings, 34 ns was applied to ring \#3 during transmission to allow both acoustic waves to arrive in phase, achieving a maximum acoustic pressure at $0.6 \mathrm{~mm}$ (see Figure 12, orange points). Computing the focusing improvement factor as the ratio between maximum received echoes $(8.4 \mathrm{mVpp} / 6.59 \mathrm{mVpp})$, a $1.3 \times$ improvement factor is obtained, which is translated into an acoustic pressure of $19.4 \mathrm{kPa} \mathrm{pp}_{\mathrm{pp}}$ $\left(1.3 \times 14.9 \mathrm{kPa}_{\mathrm{pp}}\right)$. 


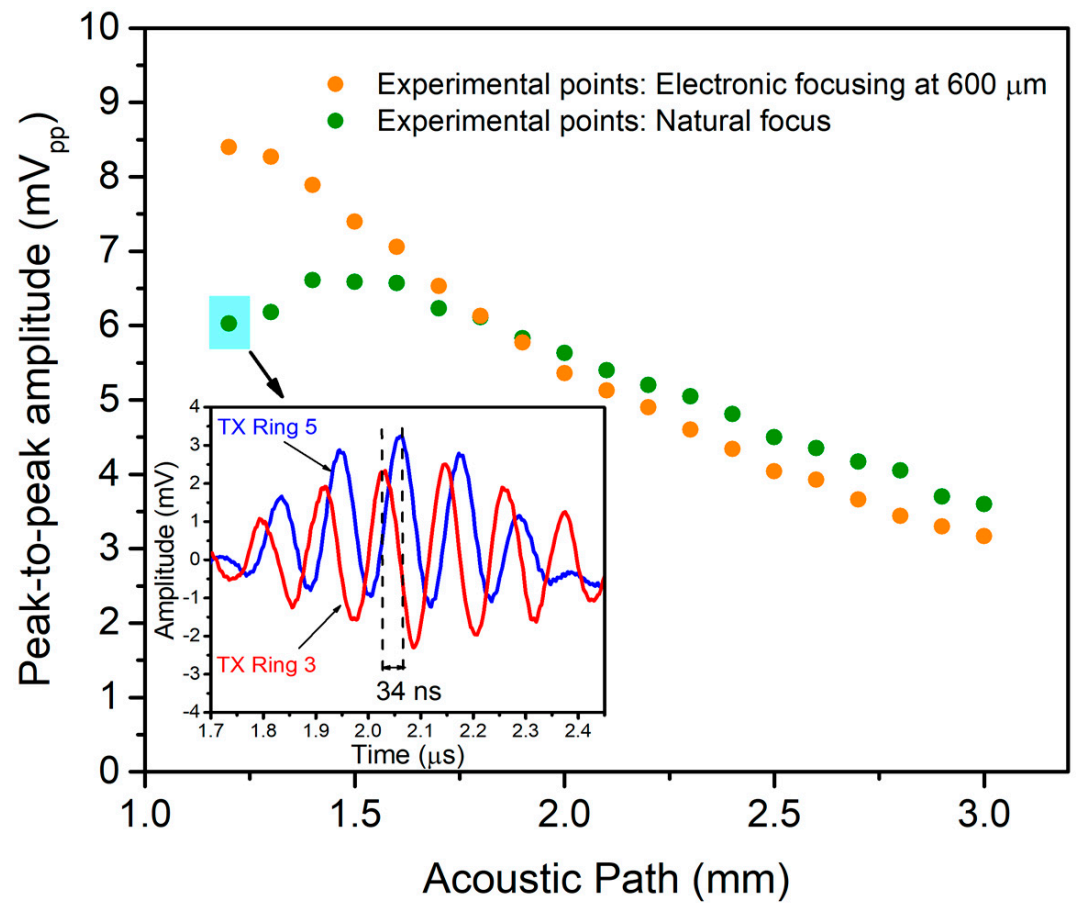

Figure 12. Voltage measured by the central ring when ring \#3 and ring \#5 are driven at the same time (green points) or electronically focused (orange points). Inset: Time-domain response of the echo signal from ring \#3 and ring \#5 to determine the needed time delay (34 ns).

\subsection{D Line-Scan Imaging}

The imaging capability was tested using a $\mathrm{Cu}$ grating phantom with three holes with different widths $(600,900$, and $1040 \mu \mathrm{m})$ and gaps $(1.2$ and $1 \mathrm{~mm})$ between them (see Figure 13 inset). The sample was immersed in FC-70 and placed at $790 \mu \mathrm{m}$ on top of the multielement ring array. A micrometric system was used to displace it along the $\mathrm{x}$-direction (perpendicular to the holes) with steps of $50 \mu \mathrm{m}$, while the y-direction was fixed at the sample's center. Two rings (\#3 and \#4) were driven with four cycles at $8.69 \mathrm{MHz}$ with $24 \mathrm{Vpp}$, and the central ring (connected to the CMOS voltage amplifier as before) was used to detect the reflected echoes (see the set-up in Figure 8).

Figure 13 (red points) show the experimental peak-to-peak amplitudes received by the central ring, giving a maximum value of around $7.5 \mathrm{mV}_{\mathrm{pp}}$ and clearly reproducing the

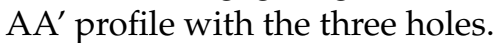

On the other hand, a scatter phantom close to the grating was modeled in Field II with the purpose of obtaining the scanning pattern under the same assumptions. The normalized signal received by the central ring when rings \#3 and \#4 are excited is shown in Figure 13 (blue points), demonstrating a good agreement with the experimental one and validating the capability to perform acoustic imaging with the multielement ring PMUT presented. 


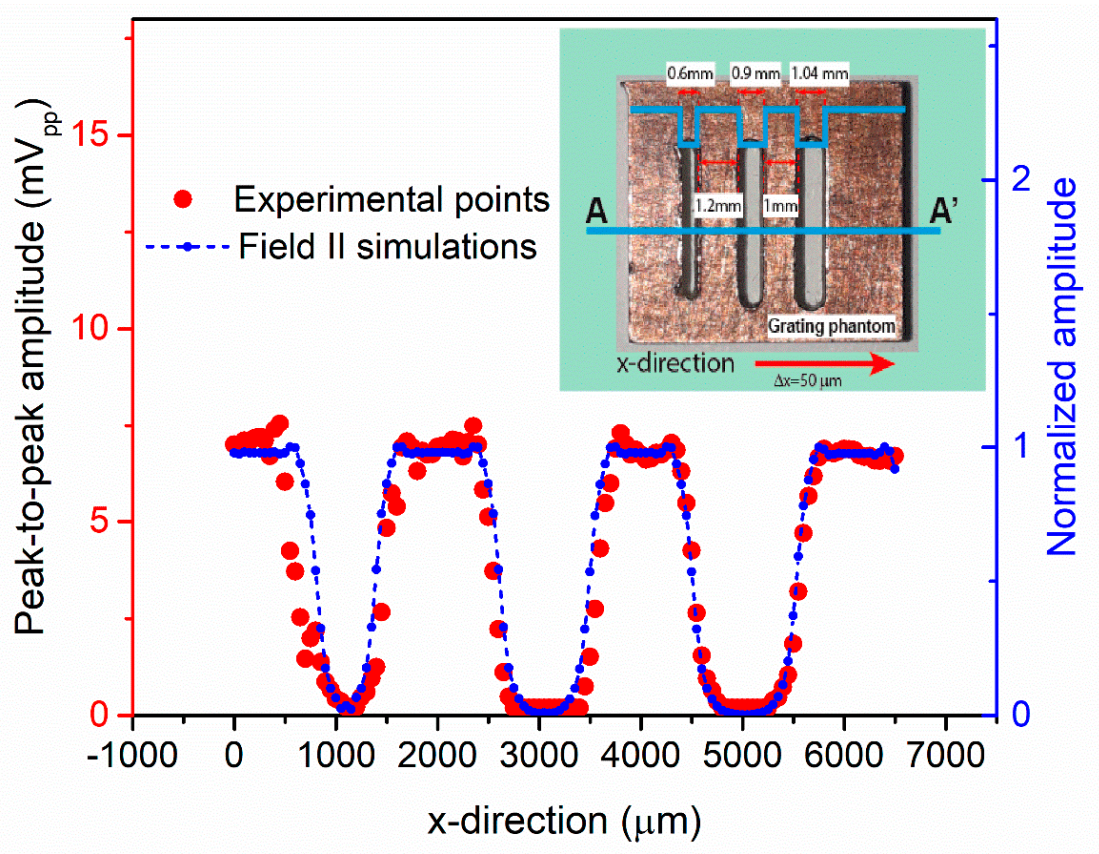

Figure 13. Pulse-echo ultrasonic 1D image of a grating phantom. Red curve: experimental points; blue curve: Field II simulations. Inset: Grating phantom with A-A' scanned profile.

\section{Conclusions}

This paper presents a multielement ring ultrasound transducer array based on AlN PMUTs fabricated with a MEMS-on-CMOS process. The presented multielement ring array eliminates the dependence of acoustic wave frequency on the diameters of the annular array and achieves accurate control of the focus depth (from $67 \mu \mathrm{m}$ to $1.4 \mathrm{~mm}$ ), which is 4.9 times greater than that of the equivalent continuous ring array. The low crosstalk between different rings (levels under $-56.8 \mathrm{~dB}$ ) allows it to be used in modern ultrasound applications where the maximum of the ultrasound beam must be controlled efficiently in the axial direction. The PMUT-based ring array, with a very reduced area, generates high pressure levels $\left(4.84 \mathrm{kPa} / \mathrm{V} / \mathrm{mm}^{2}\right.$ at $\left.1.5 \mathrm{~mm}\right)$ at $8.7 \mathrm{MHz}$ in a liquid environment, being very competitive with other annular arrays using bulk piezoelectric, CMUT, or PMUT fabrication approaches. The pulse-echo experiments with a voltage amplifier (gain of $25 \mathrm{~dB}$ ) externally connected to the central ring gave a receiving sensitivity of $441.6 \mathrm{nV} / \mathrm{Pa}$, which could be increased around $700 \mathrm{nV} / \mathrm{Pa}$ when the PMUT is monolithically integrated on the CMOS circuitry. The 1D imaging test through mechanical scanning demonstrates the possibility to obtain high-performance ultrasound imaging systems. With this performance and considering its small size (below $1 \mathrm{~mm}^{2}$ ), the presented multielement ring array fabricated with a PMUT-on-CMOS technology becomes an interesting ultrasound transducer for applications in which size, cost, reliability, and performance are a must, such as wearables and catheter-based systems. Greater focal depth and output pressure can be achieved at the same frequency by increasing the number of rings within the same technology.

Author Contributions: Conceptualization, E.L., A.U., and N.B.; device design, simulations, and acoustic experiments, E.L.; validation and analysis, E.L., I.Z., and N.B.; writing-original draft preparation, E.L.; writing-review and editing, I.Z., A.U., and N.B.; supervision, A.U. and N.B.; project administration, N.B. All authors have read and agreed to the published version of the manuscript.

Funding: This research was partially funded by the Spanish AEI with project PID2019-108270RB-I00. Institutional Review Board Statement: Not applicable.

Informed Consent Statement: Not applicable.

Data Availability Statement: Not applicable. 
Acknowledgments: Special acknowledges to SilTerra's MEMS and SENSORS technology development team for support in fabricating the PMUT-on-CMOS.

Conflicts of Interest: The authors declare no conflict of interest.

\section{References}

1. Dangi, A.; Agrawal, S.; Tiwari, S.; Jadhav, S.; Cheng, C.; Datta, G.R.; Troiler-McKinstry, S.; Pratap, R.; Kothapalli, S.-R. Ring PMUT array based miniaturized photoacoustic endoscopy device. In Proceedings of the Photons Plus Ultrasound: Imaging and Sensing 2019, San Francisco, CA, USA, 3-6 February 2019; p. 1087811.

2. Janjic, J.; Tan, M.; Daeichin, V.; Noothout, E.; Chen, C.; Chen, Z.; Chang, Z.Y.; Beurskens, R.H.S.H.; Van Soest, G.; Van Der Steen, A.F.W.; et al. A 2-D Ultrasound Transducer With Front-End ASIC and Low Cable Count for 3-D Forward-Looking Intravascular Imaging: Performance and Characterization. IEEE Trans. Ultrason. Ferroelectr. Freq. Control 2018, 65, 1832-1844. [CrossRef]

3. Moini, A.; Nikoozadeh, A.; Choe, J.W.; Chang, C.; Stephens, D.N.; Sahn, D.J.; Khuri-Yakub, P.T. Fully integrated 2D CMUT ring arrays for endoscopic ultrasound. In Proceedings of the IEEE International Ultrasonics Symposium, IUS, Tours, France, 18-21 September 2016; pp. 9-12.

4. Zahorian, J.; Hochman, M.; Xu, T.; Satir, S.; Gurun, G.; Karaman, M.; Degertekin, F.L. Monolithic CMUT-on-CMOS integration for intravascular ultrasound applications. IEEE Trans. Ultrason. Ferroelectr. Freq. Control 2011, 58, 2659-2667. [CrossRef] [PubMed]

5. Bawiec, C.R.; N’Djin, W.A.; Bouchoux, G.; Sénégond, N.; Guillen, N.; Chapelon, J.Y. Preliminary Investigation of a 64-element Capacitive Micromachined Ultrasound Transducer (CMUT) Annular Array Designed for High Intensity Focused Ultrasound (HIFU). IRBM 2018, 39, 295-306. [CrossRef]

6. Eovino, B.E.; Liang, Y.; Lin, L. Concentric PMUT Arrays for Focused Ultrasound and High Intensity Applications. In Proceedings of the 2019 IEEE 32nd International Conference on Micro Electro Mechanical Systems (MEMS), Seoul, Korea, 27-31 January 2019; pp. 771-774.

7. Li, G.; Qiu, W.; Zhang, Z.; Jiang, Q.; Su, M.; Cai, R.; Li, Y.; Cai, F.; Deng, Z.; Xu, D.; et al. Noninvasive Ultrasonic Neuromodulation in Freely Moving Mice. IEEE Trans. Biomed. Eng. 2019, 66, 217-224. [CrossRef] [PubMed]

8. Kim, H.; Kim, S.; Sim, N.S.; Pasquinelli, C.; Thielscher, A.; Lee, J.H.; Lee, H.J. Miniature ultrasound ring array transducers for transcranial ultrasound neuromodulation of freely-moving small animals. Brain Stimul. 2019, 12, 251-255. [CrossRef] [PubMed]

9. Hosseini, S.; Laursen, K.; Rashidi, A.; Mondal, T.; Corbett, B.; Moradi, F. S-MRUT: Sectored-Multiring Ultrasonic Transducer for Selective Powering of Brain Implants. IEEE Trans. Ultrason. Ferroelectr. Freq. Control 2021, 68, 191-200. [CrossRef] [PubMed]

10. Weber, M.J.; Yoshihara, Y.; Sawaby, A.; Charthad, J.; Chang, T.C.; Arbabian, A. A Miniaturized Single-Transducer Implantable Pressure Sensor with Time-Multiplexed Ultrasonic Data and Power Links. IEEE J. Solid-State Circuits 2018, 53, 1089-1101. [CrossRef]

11. Shi, C.; Andino-Pavlovsky, V.; Lee, S.A.; Costa, T.; Elloian, J.; Konofagou, E.E.; Shepard, K.L. Application of a sub-0.1-mm ${ }^{3}$ implantable mote for in vivo real-time wireless temperature sensing. Sci. Adv. 2021, 7, 1-10. [CrossRef]

12. Wang, J.; Zheng, Z.; Chan, J.; Yeow, J.T.W. Capacitive micromachined ultrasound transducers for intravascular ultrasound imaging. Microsyst. Nanoeng. 2020, 6, 73. [CrossRef]

13. Wang, D.; Filoux, E.; Levassort, F.; Lethiecq, M.; Rocks, S.A.; Dorey, R.A. Fabrication and characterization of annular-array, high-frequency, ultrasonic transducers based on PZT thick film. Sensors Actuators A Phys. 2014, 216, 207-213. [CrossRef]

14. Brenner, K.; Ergun, A.S.; Firouzi, K.; Rasmussen, M.F.; Stedman, Q.; Khuri-Yakub, B. Advances in capacitive micromachined ultrasonic transducers. Micromachines 2019, 10, 152. [CrossRef]

15. Jiang, X.; Lu, Y.; Tang, H.-Y.; Tsai, J.M.; Ng, E.J.; Daneman, M.J.; Boser, B.E.; Horsley, D.A. Monolithic ultrasound fingerprint sensor. Microsyst. Nanoeng. 2017, 3, 17059. [CrossRef]

16. Zamora, I.; Ledesma, E.; Uranga, A.; Barniol, N. Monolithic Single PMUT-on-CMOS Ultrasound System with $+17 \mathrm{~dB}$ SNR for Imaging Applications. IEEE Access 2020, 8, 142785-142794. [CrossRef]

17. Lu, Y.; Heidari, A.; Horsley, D.A. A High Fill-Factor Annular Array of High Frequency Piezoelectric Micromachined Ultrasonic Transducers. J. Microelectromechanical Syst. 2015, 24, 904-913. [CrossRef]

18. Blackstock, D.T. Fundamentals of Physical Acoustics; John Wiley \& Sons: New York, NY, USA, $2000 ;$ ISBN 0471319791.

19. Blevins, R.D. Formulas for Natural Frequency and Mode Shape; Van Nostrand Reinhold Co., Ed.; Litton Educational Publishing, Inc.: New York, NY, USA, 1979.

20. Horsley, D.; Lu, Y.; Rozen, O. Flexural Piezoelectric Resonators. In Piezoelectric MEMS Resonators; Bhugra, H., Piazza, G., Eds.; Springer International: Cham, Switzerland, 2017; pp. 153-173, ISBN 9783319286884.

21. Ledesma, E.; Zamora, I.; Uranga, A.; Barniol, N. Tent-plate AIN PMUT with a piston-like shape under liquid operation. IEEE Sens. J. 2020, 20, 11128-11137. [CrossRef]

22. Amabili, M.; Frosali, G.; Kwak, M.K. Free vibrations of annular plates coupled with fluids. J. Sound Vib. 1996, 191, 825-846. [CrossRef]

23. Jensen, J.A.; Svendsen, N.B. Calculation of pressure fields from arbitrarily shaped, apodized, and excited ultrasound transducers. Ultrason. Ferroelectr. Freq. Control. IEEE Trans. 1992, 39, 262-267. [CrossRef] [PubMed]

24. Jensen, J.A. Field: A program for simulating ultrasound systems. Med. Biol. Eng. Comput. 1996, 34, 351-352.

25. Przybyla, R.J.; Tang, H.; Member, S.; Guedes, A.; Shelton, S.E.; Horsley, D.A.; Boser, B.E. 3D Ultrasonic Rangefinder on a Chip. IEEE J. Solid-State Circuits 2015, 50, 320-334. [CrossRef] 
26. Ledesma, E.; Zamora, I.; Tzanov, V.; Torres, F.; Uranga, A.; Barniol, N.; Marigó, E.; Soundara-Pandian, M. Liquid operable AlN PMUT with high output pressure capabilities. In Proceedings of the 2019 IEEE International Ultrasonics Symposium (IUS), Glasgow, UK, 6-9 October 2019; pp. 251-254.

27. He, L.M.; Xu, W.J.; Liu, W.J.; Wang, X.B.; Zhou, J.; Ren, J.Y. Performance and Crosstalk Evaluation of 2-D Array Piezoelectric Micromachined Ultrasonic Transducer with 3-D Finite Element Simulation. In Proceedings of the IEEE International Ultrasonics Symposium, IUS, Glasgow, UK, 6-9 October 2019; pp. 792-795.

28. Bernstein, J.J.; Finberg, S.L.; Houston, K.; Niles, L.C.; Daniel Chen, H.; Eric Cross, L.; Li, K.K.; Udayakumar, K. Micromachined high frequency ferroelectric sonar transducers. IEEE Trans. Ultrason. Ferroelectr. Freq. Control 1997, 44, 960-969. [CrossRef]

29. Smith, R.A. Are hydrophones of diameter $0.5 \mathrm{~mm}$ small enough to characterise diagnostic ultrasound equipment? Phys. Med. Biol. 1989, 34, 1593-1607. [CrossRef] [PubMed]

30. Cristman, P.; Oralkan, O.; Mandella, M.; Solgaard, O.; Contag, C.; Khuri-Yakub, B.T. Interdigitated annular CMUT arrays for ultrasound assisted delivery of fluorescent contrast agents. In Proceedings of the IEEE International Ultrasonics Symposium, IUS, Orlando, FL, USA, 18-21 October 2011; pp. 96-99.

31. Zamora, I.; Ledesma, E.; Uranga, A.; Barniol, N. Miniaturized 0.13- $\mu \mathrm{m}$ CMOS Front-End Analog for AlN PMUT Arrays. Sensors 2020, 20, 1205. [CrossRef] [PubMed]

32. Onda Corporation Hydrophone Handbook. Available online: http://ondacorp.com/Handbook/mobile/index.html\#p=12 (accessed on 8 June 2021). [CrossRef]

33. Precision Acoustics Ltd. $0.2 \mathrm{~mm}$ Needle Hydrophone (NH0200). Available online: https://www.acoustics.co.uk/pal/wpcontent/uploads/2016/05/nh0200-0.2mm-needle-hydrophone-tds.pdf (accessed on 8 June 2021). 